Correspondence

Peter Kämpfer

peter.kaempfer@umwelt.unigiessen.de

\section{Microbacterium agarici sp. nov., Microbacterium humi sp. nov. and Microbacterium pseudoresistens sp. nov., isolated from the base of the mushroom Agaricus blazei}

\author{
C.-C. Young, ${ }^{1}$ H.-J. Busse, ${ }^{2}$ S. Langer, ${ }^{2}$ Jiunn-Nan Chu, ${ }^{1}$ P. Schumann, ${ }^{3}$ \\ A. B. Arun, ${ }^{4}$ Fo-Ting Shen, ${ }^{1}$ P. D. Rekha ${ }^{4}$ and P. Kämpfer ${ }^{5}$ \\ ${ }^{1}$ College of Agriculture and Natural Resources, Department of Soil and Environmental Sciences, \\ National Chung Hsing University, Taichung 402, Taiwan, ROC \\ ${ }^{2}$ Institut für Bakteriologie, Mykologie und Hygiene, Veterinärmedizinische Universität, A-1210 Wien, \\ Austria \\ ${ }^{3}$ Deutsche Sammlung von Mikroorganismen und Zellkulturen, D-38124 Braunschweig, Germany \\ ${ }^{4}$ Yenepoya Research Center, Yenepoya University, University Rd, Deralakatte, Mangalore, 575018 \\ Karnataka, India \\ ${ }^{5}$ Institut für Angewandte Mikrobiologie, Justus-Liebig-Universität Giessen, D-35392 Giessen, \\ Germany
}

Three Gram-positive, rod-shaped bacteria (strains CC-SBCK-209 ${ }^{\top}$, CC- $12309^{\top}$ and CC$5209^{\top}$ ) were isolated from the stalk of the edible mushroom Agaricus blazei grown in the laboratory. 16S rRNA gene sequence analysis indicated that all three isolates clearly belonged to the genus Microbacterium. Strains CC-SBCK- $209^{\top}$ and CC $-12309^{\top}$ were most related closely to the type strain of Microbacterium halotolerans (95.9 and 96.1\% 16S rRNA gene sequence similarity, respectively). These two novel strains shared $97.9 \% 16$ rRNA gene sequence similarity. Levels of similarity to the type strains of all other recognized Microbacterium species were lower than $95.5 \%$. The third strain $\left(C C-5209^{\top}\right)$ showed the highest $16 \mathrm{~S}$ rRNA gene sequence similarity to the type strain of Microbacterium resistens (97.6\%); levels of similarity to the type strains of all other recognized Microbacterium species were lower than $96 \%$. The quinone systems of strains CC-SBCK-209 ${ }^{\top}, \mathrm{CC}-12309^{\top}$ and CC- $5209^{\top}$ consisted of MK-11/ MK-12, MK-11/MK-10 and MK-13 as major compounds, respectively. All three strains contained ornithine in their peptidoglycan. The major polar lipids were diphosphatidylglycerol,

phosphatidylglycerol and an unknown glycolipid. The polyamine pattern consisted of spermidine and spermine as predominant components. Fatty acid profiles (anteiso- $\mathrm{C}_{15: 0}$, iso- $\mathrm{C}_{16: 0}$ and anteiso- $\mathrm{C}_{17: 0}$ as major components) supported the affiliation of all three strains to the genus Microbacterium. The results of physiological and biochemical tests and DNA-DNA hybridization experiments allowed the clear phenotypic and genotypic differentiation of strains CC-SBCK-209 ${ }^{\top}$ and $C C-12309^{\top}$ from M. halotolerans and other closely related Microbacterium species. Strain CC- $5209^{\top}$ could be differentiated clearly from $M$. resistens both genotypically and phenotypically. Based on these data, the novel strains are considered to represent three novel species of the genus Microbacterium. The names proposed for these organisms are Microbacterium agarici sp. nov. [type strain CC-SBCK-209 ${ }^{\top}\left(=\mathrm{DSM} 21798^{\top}=\mathrm{CCM} 7686^{\top}\right)$ ], Microbacterium humi sp. nov. [type strain CC-12309 ${ }^{\top}\left(=\mathrm{DSM} 21799^{\top}=\mathrm{CCM} 7687^{\top}\right)$ ] and Microbacterium pseudoresistens sp. nov. [type strain CC-5209 $\left(=\mathrm{DSM} 22185^{\top}=\right.$ CCM $\left.\left.7688^{\top}\right)\right]$.

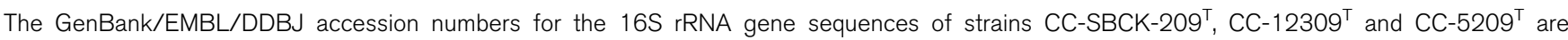
FJ807673, FJ865215 and FJ865214, respectively.

A table giving the fatty acid profiles of strains CC-12309 ${ }^{\top}$, CC-SBCK- $209^{\top}$ and CC- $5209^{\top}$ and the type strains of closely related Microbacterium species is available as supplementary material with the online version of this paper. 
The genus Microbacterium was described by Orla-Jensen (1919) and comprises a diverse collection of Grampositive, non-spore-forming rods that were isolated from various environmental habitats, including plants, soil, water, steep liquor and milk products, and also from humans. Collins et al. (1983) emended the description of the genus, and Takeuchi \& Hatano (1998) emended the description again with the unification of the genera Microbacterium and Aureobacterium.

Here we describe the phenotypic and genotypic properties of three novel Microbacterium strains isolated from an edible mushroom.

Strains CC-SBCK- $209^{\mathrm{T}}, \mathrm{CC}-12309^{\mathrm{T}}$ and CC-5209 ${ }^{\mathrm{T}}$ were isolated from the stalk of the mushroom Agaricus blazei grown in the laboratory, on nutrient agar (NA; Hi-Media) after incubation at $30{ }^{\circ} \mathrm{C}$ for $48 \mathrm{~h}$, and were maintained on NA. The strains were preserved at $-80{ }^{\circ} \mathrm{C}$ in nutrient broth (NB; Hi-Media) with $20 \%(\mathrm{v} / \mathrm{v})$ glycerol or by lyophilization.

Morphological properties, Gram-staining and cell morphology were observed by using phase-contrast microscopy as described by Kämpfer \& Kroppenstedt (2004).

The 16S rRNA gene sequences of all three strains were determined and analysed as described by Young et al. (2005). Multiple sequence alignment and analysis of the data were performed by using the software package MEGA version 4 (Tamura et al., 2007). Genetic distance calculations (distance options according to the Kimura two-parameter model) and clustering with the neighbourjoining method (Fig. 1) and maximum-parsimony method (results not shown) were performed by using bootstrap values based on 1000 replications. The 16S rRNA gene sequences of strains CC-SBCK- $209^{\mathrm{T}}$, CC- $12309^{\mathrm{T}}$ and CC$5209^{\mathrm{T}}$ were continuous stretches of 1480,1430 and $1489 \mathrm{bp}$, respectively. Strains CC-SBCK-209 ${ }^{\mathrm{T}}$ and CC$12309^{\mathrm{T}}$ shared $97.9 \% 16 \mathrm{~S}$ rRNA gene sequence similarity; these strains were related most closely to Microbacterium halotolerans DSM $15855^{\mathrm{T}}$ (95.9 and $96.1 \%$ similarity, respectively). Levels of $16 \mathrm{~S}$ rRNA gene sequence similarity between strains CC-SBCK- $209^{\mathrm{T}}$ and CC- $12309^{\mathrm{T}}$ and the type strains of all other recognized Microbacterium species were below $95.5 \%$.

Strain CC- $5209^{\mathrm{T}}$ was related most closely to the type strain of Microbacterium resistens $(97.6 \% \quad 16 \mathrm{~S}$ rRNA gene sequence similarity). Levels of less than $96 \%$ similarity were found to the type strains of all other recognized Microbacterium species.

The peptidoglycan of strains CC-SBCK- $209^{\mathrm{T}}$ and CC$12309^{\mathrm{T}}$ grown in trypticase soy yeast extract medium (medium 92; http://www.dsmz.de) and of strain CC-5209 ${ }^{\mathrm{T}}$ grown in brain heart infusion broth (Becton Dickinson) supplemented with haemin $\left(1 \mathrm{mg} \mathrm{l^{-1 }}\right)$ at $28{ }^{\circ} \mathrm{C}$ was extracted after disruption of the cells by shaking with glass beads and subsequent trypsin digestion, according to the method of Schleifer (1985). Amino acids were analysed by using GC (GC 14A; Shimadzu) and GC-MS (320-MS Quadrupole GC/MS; Varian) of N-heptafluorobutyryl amino acid isobutyl esters (MacKenzie, 1987; Groth et al., 1996). The hydrolysates $\left(4 \mathrm{M} \mathrm{HCl}, 100{ }^{\circ} \mathrm{C}, 16 \mathrm{~h}\right)$ of the purified peptidoglycan of strains CC-SBCK- $209^{\mathrm{T}}, \mathrm{CC}-12309^{\mathrm{T}}$ and CC- $5209^{\mathrm{T}}$ contained the amino acids ornithine, glycine, alanine and glutamic acid, but did not contain homoserine. Strain CC- $5209^{\mathrm{T}}$ differed from the other two novel strains because a relatively high amount of glutamic acid in the peptidoglycan was replaced by 3-hydroxyglutamic acid (Hyg) and the ratio of glycine to ornithine was lower. Peptides in the cell-wall hydrolysates were analysed by twodimensional ascending TLC on cellulose plates by using the solvent systems described by Schleifer (1985). The peptides Gly $\rightarrow$ D-Glu and D-Ala $\rightarrow$ D-Orn were detected in the partial hydrolysates $\left(4 \mathrm{M} \mathrm{HCl}, 100{ }^{\circ} \mathrm{C}, 0.75 \mathrm{~h}\right)$ of the peptidoglycan of all three strains. The peptides Gly $\rightarrow$ D-Orn and Gly $\rightarrow$ DOrn $\leftarrow$ D-Ala were detected only in strains CC-SBCK- $209^{\mathrm{T}}$ and CC- $12309^{\mathrm{T}}$. These data suggested that the peptidoglycan of strains CC-SBCK- $209^{\mathrm{T}}$ and CC- $12309^{\mathrm{T}}$ is of type $\mathrm{B} 2 \alpha$ with an interpeptide bridge $\mathrm{D}$-Glu $\rightarrow \mathrm{Gly} \rightarrow \mathrm{D}$-Orn (Schleifer \& Kandler, 1972; B12 according to http://www.dsmz.de/ microorganisms/main.php?content_id=35). The data supported the view that the peptidoglycan of strain CC $-5209^{\mathrm{T}}$ is of type B2 $\alpha$ with an interpeptide bridge D-Glu $\rightarrow$ D-Orn (Schleifer \& Kandler, 1972; B9 according to http://www. dsmz.de/microorganisms/main.php?content_id=35), which was found also in its phylogenetic neighbour, M. resistens (Funke et al., 1998). For polyamine, quinone and polar lipid analyses, cells were grown at $30{ }^{\circ} \mathrm{C}$ for $48 \mathrm{~h}$ in PYE medium $(0.3 \%$ peptone from casein, $0.3 \%$ yeast extract, $\mathrm{pH} 7.2)$. Polyamines were extracted and analysed as described by Altenburger et al. (1997). Analyses of quinones and polar lipids were carried out according to Tindall (1990a, b) and Altenburger et al. (1996). The HPLC system used for analysis of quinones and polyamines was equipped as described by Stolz et al. (2007).

The polyamine pattern of strain CC-SBCK- $209^{\mathrm{T}}$ contained $4.2 \mu \mathrm{mol}$ spermidine ( $\mathrm{g}$ dry weight $)^{-1}$ and $3.6 \mu \mathrm{mol}$ spermine $(\mathrm{g} \text { dry weight })^{-1}$, the polyamine pattern of strain CC- $12309^{\mathrm{T}}$ contained $0.9 \mu \mathrm{mol}$ spermidine (g dry weight $)^{-1}$ and $1.3 \mu \mathrm{mol}$ spermine $(\mathrm{g} \text { dry weight })^{-1}$, and the polyamine pattern of strain $\mathrm{CC}-5209^{\mathrm{T}}$ contained $0.3 \mu \mathrm{mol}$ spermidine (g dry weight) ${ }^{-1}$ and $0.1 \mu \mathrm{mol}$ spermine ( $\mathrm{g}$ dry weight $)^{-1}$. The three novel strains also contained trace amounts of putrescine or putrescine and cadaverine $\left.[<0.1 \mu \mathrm{mol} \text { (g dry weight })^{-1}\right]$. The relatively high polyamine contents in strains CC-SBCK- $209^{\mathrm{T}}$ and CC $-12309^{\mathrm{T}}$ can be used to differentiate the two strains from recognized Microbacterium species. This polyamine pattern is rare among other examined microbacteria (Altenburger et al., 1997). Only Microbacterium aurum was reported to contain these major polyamines in concentrations corresponding to those of strain CC$12309^{\mathrm{T}}$. The quinone system of strain CC- $12309^{\mathrm{T}}$ consisted of MK-11 (52\%), MK-10 (37\%) and MK-12 (11\%), similar to that reported for M. halotolerans (Li et al., 2005). 


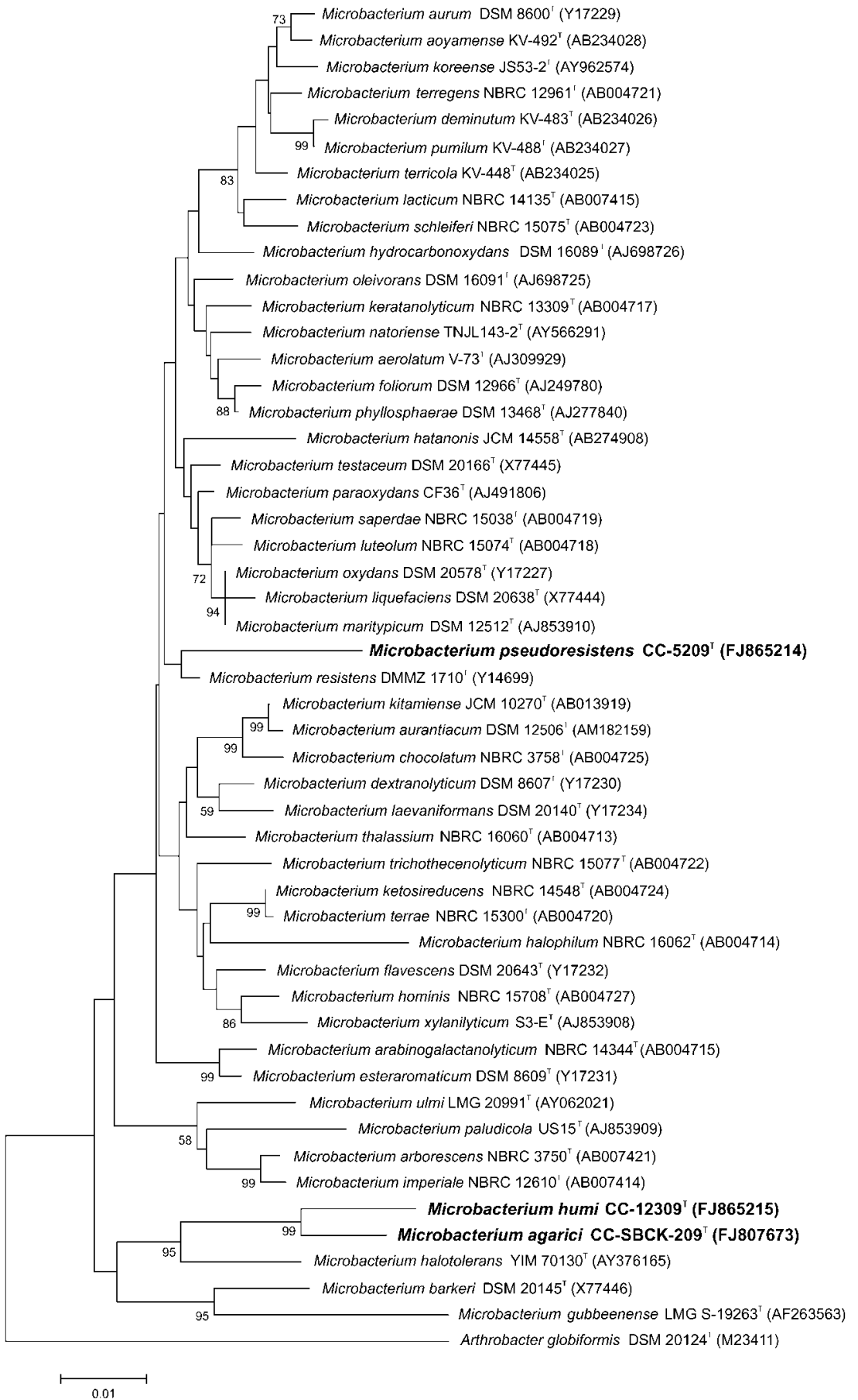

Fig. 1. Neighbour-joining phylogenetic analysis based on 16S rRNA gene sequences showing the positions of strains CC-SBCK$209^{\top}, \mathrm{CC}-12309^{\top}$ and CC-5209 ${ }^{\top}$ among the type strains of selected Microbacterium species available from GenBank/EMBL/DDBJ (accession numbers are given in parentheses). Bootstrap values based on 1000 replications are listed as percentages at branch points. Bar, 0.01 substitutions per nucleotide position.
The quinone system of strain CC-SBCK-209 ${ }^{\mathrm{T}}$ consisted of MK-11 (59\%), MK-12 (36\%) and MK-10 (5\%), clearly distinguishing it from strain CC- $12309^{\mathrm{T}}$ and from M. halotolerans. The quinone system of strain CC-5209 ${ }^{\mathrm{T}}$ comprised MK-13 (92\%) as the major compound, with minor amounts of MK-12 (4\%) and MK-14 (4\%). It can be assumed that examination of additional strains of any of these species would show very similar quinone systems, as it has been shown that the relative amounts of the major quinones for four strains of Microbacterium paraoxydans are quite stable (Buczolits et al., 2008). Strains CC-SBCK$209^{\mathrm{T}}$, CC- $12309^{\mathrm{T}}$ and $\mathrm{CC}-5209^{\mathrm{T}}$ exhibited polar lipid profiles consisting of the major components diphosphatidylglycerol, phosphatidylglycerol and an unknown glycolipid that showed identical behaviour during TLC analyses of the extracts of the three strains. These major polar lipids have been detected in numerous Microbacterium species (Zlamala et al., 2002; Rivas et al., 2004; Kim et al., 2005; Shivaji et al., 2007; Buczolits et al., 2008; Park et al., 2006) and they have also been listed in the emended description 
of the genus (Takeuchi \& Hatano, 1998). In addition, in the extract from strain CC-SBCK-209 ${ }^{\mathrm{T}}$, minor amounts of a second unknown glycolipid and two unknown phospholipids were detected (Fig. 2). Although no additional lipids were detected in strain CC- $12309^{\mathrm{T}}$, trace amounts of three lipids not detectable with any of the specific reagents used (molybdenum blue, ninhydrin, $\alpha$-naphthol) were detected in the extract of strain CC-5209 ${ }^{\mathrm{T}}$. However, these polar lipid profiles are in accordance with the placement of the three strains in the genus Microbacterium.

Fatty acid analysis was performed according to Kämpfer \& Kroppenstedt (1996). The fatty acid profiles of all three strains were very similar to those of closely related Microbacterium species (see Supplementary Table S1, available in IJSEM Online). A fatty acid profile typical of the genus, with anteiso- $\mathrm{C}_{15: 0}$, iso- $\mathrm{C}_{16: 0}$ and anteiso- $\mathrm{C}_{17: 0}$ as major components, was found.

Results of comparative physiological characterization under identical test conditions (Kämpfer et al., 1991) are given for strains CC-SBCK-209 ${ }^{\mathrm{T}}$ and CC- $12309^{\mathrm{T}}$ in comparison with the type strains of $M$. halotolerans, Microbacterium gubbeenense and Microbacterium barkeri in Table 1 and in the species descriptions below. DNADNA hybridization experiments were performed with strains CC-SBCK $-209^{\mathrm{T}}$ and CC- $12309^{\mathrm{T}}$ and M. halotolerans DSM $15855^{\mathrm{T}}$ according to the method of Ziemke et al. (1998). Levels of DNA-DNA relatedness between strains CC-SBCK- $209^{\mathrm{T}}$ and CC- $12309^{\mathrm{T}}$ were 45 and $49 \%$ (reciprocal analyses). The level of DNA-DNA relatedness between strain CC-SBCK- $209^{\mathrm{T}}$ and M. halotolerans DSM $15855^{\mathrm{T}}$ was $26 \%$ (14.1\% reciprocal analysis) and between strain CC- $12309^{\mathrm{T}}$ and $M$. halotolerans DSM $15855^{\mathrm{T}}$ was $21.5 \%$ (21.1\% reciprocal analysis).
Table 1 also provides a comparison of the phenotypic characteristics of strain CC- $5209^{\mathrm{T}}$ and the type strain of M. resistens. The level of DNA-DNA relatedness between strain CC-5209 ${ }^{\mathrm{T}}$ and M. resistens CCUG $38312^{\mathrm{T}}$ was $42 \%$ (34.1\% reciprocal analysis).

Peptidoglycan types, quinone systems, fatty acid and polar lipid profiles as well as $16 \mathrm{~S}$ rRNA gene sequence analyses showed unambiguously that strains CC-SBCK-209 ${ }^{\mathrm{T}}$, CC$12309^{\mathrm{T}}$ and CC-5209 ${ }^{\mathrm{T}}$ are affiliated with the genus Microbacterium. On the basis of observed phenotypic differences, the results of DNA-DNA hybridization experiments and differences in $16 \mathrm{~S}$ rRNA gene sequences we propose that these strains represent novel species of the genus Microbacterium, for which the names Microbacterium agarici sp. nov., Microbacterium humi sp. nov. and Microbacterium pseudoresistens sp. nov. are proposed.

\section{Description of Microbacterium agarici sp. nov.}

Microbacterium agarici (a.ga.ri'ci. N.L. gen. n. agarici of Agaricus, the generic name of the mushroom Agaricus blazei from where the type strain was isolated).

Cells are short rods, about 2-3 $\mu \mathrm{m}$ in length and 1-1.2 $\mu \mathrm{m}$ in width. Cells are Gram-positive, oxidase-positive and catalase-positive, showing aerobic respiratory metabolism. Good growth occurs after 3 days incubation on R2A agar (Oxoid) and NA at $25-30{ }^{\circ} \mathrm{C}$; colonies on NA are yellow. The peptidoglycan is of type $\mathrm{B} 2 \alpha$ with an interpeptide bridge $\mathrm{D}-\mathrm{Glu} \rightarrow \mathrm{Gly} \rightarrow \mathrm{D}-\mathrm{Orn}$. The quinone system is composed of the major components MK-11 and MK-12 and minor amounts of MK-10. The polar lipid profile consists of diphosphatidylglycerol, phosphatidylglycerol and an unknown glycolipid, plus minor amounts of two unknown

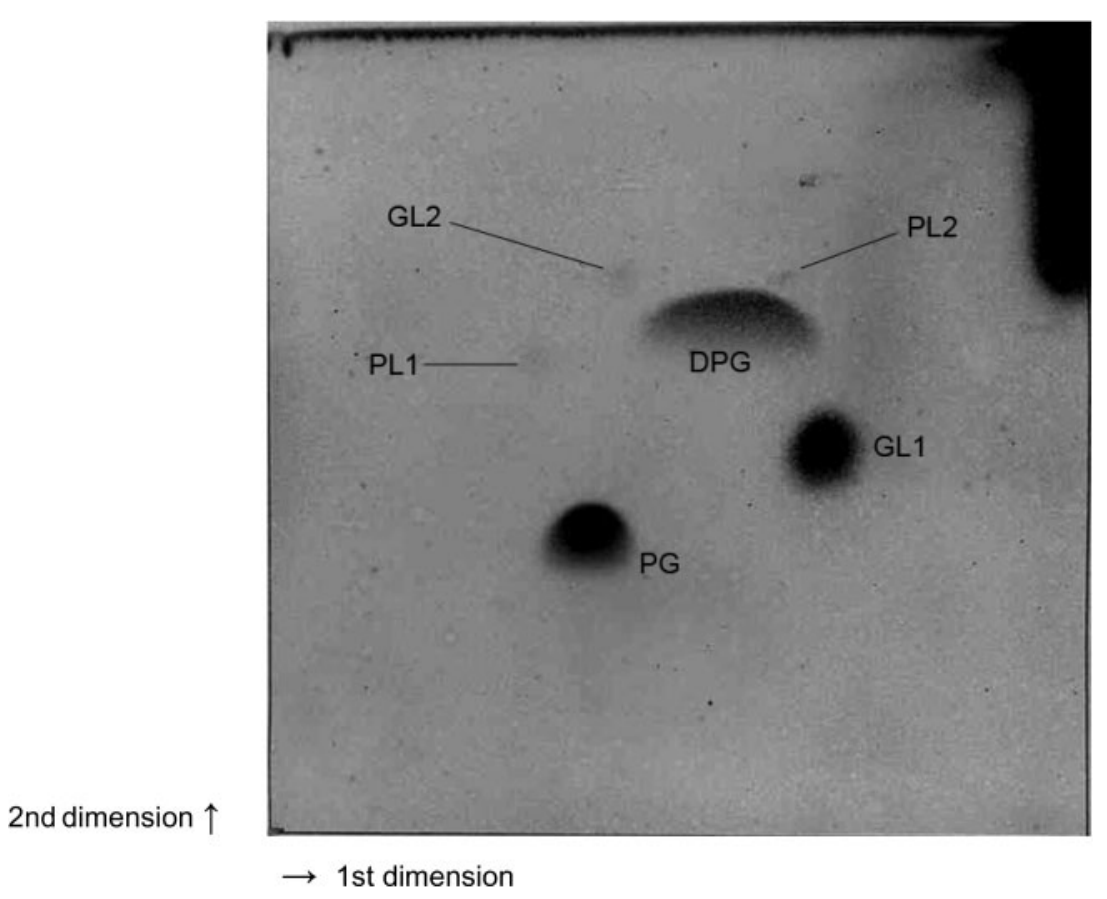

Fig. 2. Polar lipid profile of strain CC-SBCK$209^{\top}$ after two-dimensional TLC and detection with molybdatophosphoric acid. Abbreviations: DPG, diphosphatidylglycerol; GL1, GL2, unknown glycolipids; PG, phosphatidylglycerol; PL1, PL2, unknown phospholipids. 
Table 1. Differential physiological characteristics between strains CC-12309 ${ }^{\top}, C C-S B C K-209^{\top}, C C-5209^{\top}$ and the type strains of closely related Microbacterium species

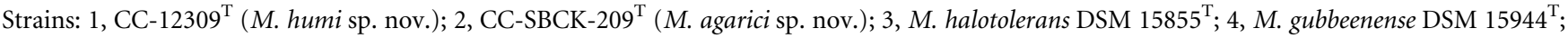
5, M. barkeri JCM $1343^{\mathrm{T}} ; 6$, CC-5209 ${ }^{\mathrm{T}}$ (M. pseudoresistens sp. nov.); 7, M. resistens CCUG $38312^{\mathrm{T}}$. All data are from the present study. Acid production from D-arabitol, dulcitol, erythritol, maltose, melibiose, methyl D-glucoside, raffinose, rhamnose, salicin, sorbitol and trehalose was negative for all strains. All strains hydrolysed aesculin, pNP- $\alpha$-D-glucopyranoside, pNP- $\beta$-D-glucopyranoside and L-alanine-pNA (oNP, $o$ nitrophenyl; pNP, p-nitrophenyl; pNA, p-nitroanilide). All strains utilized cellobiose, D-fructose, D-glucose, DL-lactate, D-mannose, maltose, Dmannitol, L-proline, sucrose and trehalose as sole carbon source. None of the strains was able to utilize $N$-acetyl-D-galactosamine, trans-aconitate, adipate, 4-aminobutyrate, azelate, glutarate, DL-3-hydroxybutyrate, itaconate, L-leucine, mesaconate, phenylacetate, L-phenylalanine, suberate or Ltryptophan. +, Positive; -, negative, (+), weakly positive.

\begin{tabular}{|c|c|c|c|c|c|c|c|}
\hline Characteristic & 1 & 2 & 3 & 4 & 5 & 6 & 7 \\
\hline \multicolumn{8}{|l|}{ Acid production from: } \\
\hline Adonitol & - & $(+)$ & - & - & - & - & - \\
\hline L-Arabinose & - & - & - & - & + & - & - \\
\hline Cellobiose & - & - & - & - & + & - & - \\
\hline Glucose & $(+)$ & - & - & - & + & - & - \\
\hline Lactose & $(+)$ & - & - & - & - & - & - \\
\hline D-Mannitol & + & + & + & + & + & - & - \\
\hline D-Mannose & - & - & - & - & + & - & - \\
\hline Sucrose & + & - & - & - & - & - & - \\
\hline D-Xylose & - & - & - & - & + & - & - \\
\hline \multicolumn{8}{|l|}{ Hydrolysis of: } \\
\hline Aesculin & + & $(+)$ & + & + & + & + & + \\
\hline oNP- $\beta$-D-galactopyranoside & + & + & + & + & + & - & + \\
\hline pNP- $\beta$-D-glucuronide & + & - & - & - & - & - & - \\
\hline pNP- $\beta$-D-xylopyranoside & + & + & + & + & + & - & + \\
\hline Bis-pNP-phosphate & + & - & + & + & + & - & + \\
\hline pNP-phenyl-phosphonate & + & - & + & + & + & + & + \\
\hline pNP-phosphoryl-choline & - & - & - & - & - & - & + \\
\hline 2-Deoxythymidine-5'-pNP-phosphate & - & - & - & - & + & - & + \\
\hline L-Glutamate- $\gamma-3$-carboxy-pNA & - & - & - & - & - & - & + \\
\hline L-Proline-pNA & - & + & + & + & + & + & + \\
\hline \multicolumn{8}{|l|}{ Assimilation of: } \\
\hline $\mathrm{N}$-Acetyl-D-glucosamine & + & - & + & + & + & + & + \\
\hline L-Arabinose & + & + & + & + & + & - & + \\
\hline p-Arbutin & - & - & + & + & + & - & + \\
\hline D-Galactose & + & + & + & + & + & - & + \\
\hline Gluconate & - & - & + & + & + & - & + \\
\hline$\alpha$-Melibiose & + & - & - & - & + & - & - \\
\hline L-Rhamnose & + & + & + & + & + & - & + \\
\hline D-Ribose & + & + & + & + & + & + & + \\
\hline Salicin & - & + & + & + & + & + & + \\
\hline D-Xylose & + & + & + & - & + & - & $(+)$ \\
\hline Adonitol & - & + & - & - & - & - & $(+)$ \\
\hline i-Inositol & - & - & - & - & + & - & - \\
\hline Maltitol & + & + & - & - & + & - & + \\
\hline D-Sorbitol & + & + & + & - & - & - & $(+)$ \\
\hline Putrescine & - & + & - & - & + & - & - \\
\hline Acetate & - & - & - & $(+)$ & + & - & + \\
\hline Propionate & - & - & - & $(+)$ & + & - & + \\
\hline cis-Aconitate & - & - & + & + & + & - & - \\
\hline Citrate & - & - & + & + & + & - & + \\
\hline Fumarate & + & - & - & - & + & $(+)$ & - \\
\hline L-Malate & + & + & - & - & + & - & - \\
\hline Oxoglutarate & + & - & - & - & + & - & - \\
\hline Pyruvate & + & - & + & + & + & - & + \\
\hline L-Alanine & - & - & + & + & + & - & + \\
\hline
\end{tabular}


Table 1. cont.

\begin{tabular}{|c|c|c|c|c|c|c|c|}
\hline Characteristic & 1 & 2 & 3 & 4 & 5 & 6 & 7 \\
\hline$\beta$-Alanine & - & - & - & + & - & - & - \\
\hline L-Aspartate & + & + & + & + & + & - & - \\
\hline L-Ornithine & - & - & - & + & - & - & - \\
\hline L-Serine & - & - & - & + & + & - & - \\
\hline 3-Hydroxybenzoate & - & - & + & - & + & - & - \\
\hline
\end{tabular}

phospholipids and another glycolipid. The predominant polyamines are spermidine and spermine. Major fatty acids are anteiso- $\mathrm{C}_{15: 0}$, iso- $\mathrm{C}_{16: 0}$ and anteiso- $\mathrm{C}_{17: 0}$. Differential physiological characteristics are given in Table 1. Many sugar and other compounds are utilized, including salicin, D-adonitol and putrescine, but not $N$-acetyl-D-glucosamine, $\alpha$-melibiose or fumarate.

The type strain, CC-SBCK- $209^{\mathrm{T}}\left(=\mathrm{DSM} 21798^{\mathrm{T}}=\mathrm{CCM}\right.$ $7686^{\mathrm{T}}$ ), was isolated from the stalk of the edible mushroom Agaricus blazei grown in the laboratory.

\section{Description of Microbacterium humi sp. nov.}

Microbacterium humi (hu'mi. L. gen. n. humi of earth, soil, of soil, the source of the type strain).

Cells are short rods, about $2-3 \mu \mathrm{m}$ in length and 1-1.2 $\mu \mathrm{m}$ in width. Cells are Gram-positive, oxidase-positive and catalase-positive, showing aerobic respiratory metabolism. Good growth occurs after 3 days incubation on R2A agar and NA at $25-30{ }^{\circ} \mathrm{C}$; colonies on NA are yellow. The peptidoglycan is of type $\mathrm{B} 2 \alpha$ with an interpeptide bridge $\mathrm{D}$ Glu $\rightarrow$ Gly $\rightarrow$ D-Orn. The quinone system is composed of the major components MK-11 and MK-10 and minor amounts of MK-12. The polar lipid profile consists of diphosphatidylglycerol, phosphatidylglycerol and an unknown glycolipid. The predominant polyamines are spermidine and spermine. Major fatty acids are anteiso- $\mathrm{C}_{15: 0}$, iso- $\mathrm{C}_{16: 0}$ and anteiso- $\mathrm{C}_{17: 0}$. Differential physiological characteristics are given in Table 1. Many sugars and other compounds are utilized, including $N$-acetyl-D-glucosamine, $\alpha$-melibiose and fumarate, but not salicin, $\mathrm{D}$-adonitol or putrescine.

The type strain, CC $-12309^{\mathrm{T}} \quad\left(=\mathrm{DSM} \quad 21799^{\mathrm{T}}=\mathrm{CCM}\right.$ $7687^{\mathrm{T}}$ ), was isolated from the stalk of the edible mushroom Agaricus blazei grown in the laboratory.

\section{Description of Microbacterium pseudoresistens sp. nov.}

Microbacterium pseudoresistens (pseu.do.re.sis'tens. Gr. adj. pseudes false; L. part adj. resistens resisting and also a bacterial specific epithet; N.L. part. adj. pseudoresistens the false Microbacterium resistens).

Cells are short rods, about $2-3 \mu \mathrm{m}$ in length and 1-1.2 $\mu \mathrm{m}$ in width. Cells are Gram-positive, oxidase-positive and catalase-positive, showing aerobic respiratory metabolism. Good growth occurs after 3 days incubation on R2A agar and NA at $25-30{ }^{\circ} \mathrm{C}$; colonies on NA are yellow. The peptidoglycan is of type $\mathrm{B} 2 \alpha$ with an interpeptide bridge DGlu $\rightarrow$ D-Orn. The quinone system is composed of the predominant menaquinone MK-13 with minor amounts of MK-12 and MK-14. The polar lipid profile consists of diphosphatidylglycerol, phosphatidylglycerol and an unknown glycolipid and trace amounts of three unknown lipids. The predominant polyamines are spermidine and spermine. Major fatty acids are anteiso- $\mathrm{C}_{15: 0}$, iso- $\mathrm{C}_{16: 0}$ and anteiso- $\mathrm{C}_{17: 0}$. Differential physiological characteristics are given in Table 1. Many sugar and other compounds utilized by $M$. resistens CCUG $38312^{\mathrm{T}}$ are not utilized, including D-galactose, L-rhamnose and acetate.

The type strain, CC $-5209^{\mathrm{T}}\left(=\mathrm{DSM} 22185^{\mathrm{T}}=\mathrm{CCM} 7688^{\mathrm{T}}\right)$, was isolated from the stalk of the edible mushroom Agaricus blazei grown in the laboratory.

\section{Acknowledgements}

We are grateful to Anika Wasner (DSMZ), Gundula Will and W. S. Huang for excellent technical assistance and 16S rRNA gene sequencing. This research was supported by a grant from the National Science Council, and Council of Agriculture, Executive Yuan, Taiwan, ROC.

\section{References}

Altenburger, P., Kämpfer, P., Makristathis, A., Lubitz, W. \& Busse, H.-J. (1996). Classification of bacteria isolated from a medieval wall painting. J Biotechnol 47, 39-52.

Altenburger, P., Kämpfer, P., Akimov, V. N., Lubitz, W. \& Busse, H.-J. (1997). Polyamine distribution in actinomycetes with group B peptidoglycan and species of the genera Brevibacterium, Corynebacterium and Tsukamurella. Int J Syst Bacteriol 47, 270-277.

Buczolits, S., Schumann, P., Valens, M., Rosselló-Mora, R. \& Busse, H.-J. (2008). Identification of a bacterial strain isolated from the liver of a laboratory mouse as Microbacterium paraoxydans and emended description of the species Microbacterium paraoxydans Laffineur et al. 2003. Ind J Microbiol 48, 243-251.

Collins, M. D., Jones, D. \& Kroppenstedt, R. M. (1983). Reclassification of Brevibacterium imperiale (Steinhaus) and "Corynebacterium laevaniformans" (Dias and Bhat) in a redefined genus Microbacterium (Orla-Jensen) as Microbacterium imperiale comb. nov. and Microbacterium laevaniformans nom. rev.; comb. nov. Syst Appl Microbiol 4, 65-78. 
Funke, G., Lawson, P. A., Nolte, F. S., Weiss, N. \& Collins, M. D. (1998). Aureobacterium resistens sp. nov., exhibiting vancomycin resistance and teicoplanin susceptibility. FEMS Microbiol Lett 158, 89-93.

Groth, I., Schumann, P., Weiss, N., Martin, K. \& Rainey, F. A. (1996). Agrococcus jenensis gen. nov., sp. nov., a new genus of actinomycetes with diaminobutyric acid in the cell wall. Int J Syst Bacteriol 46, 234239.

Kämpfer, P. \& Kroppenstedt, R. M. (1996). Numerical analysis of fatty acid patterns of coryneform bacteria and related taxa. Can J Microbiol 42, 989-1005.

Kämpfer, P. \& Kroppenstedt, R. M. (2004). Microbacterium benzenivorans sp. nov. Int J Syst Evol Microbiol 54, 749-751.

Kämpfer, P., Steiof, M. \& Dott, W. (1991). Microbiological characterization of a fuel-oil contaminated site including numerical identification of heterotrophic water and soil bacteria. Microb Ecol 21, 227-251.

Kim, K. K., Park, H. Y., Park, W., Kim, I. S. \& Lee, S.-T. (2005). Microbacterium xylanilyticum sp. nov., a xylan-degrading bacterium isolated from a biofilm. Int J Syst Evol Microbiol 55, 2075-2079.

Li, W.-J., Chen, H.-H., Kim, C.-J., Park, D.-J., Tang, S.-K., Lee, J.-C., Xu, L.-H. \& Jiang, C.-L. (2005). Microbacterium halotolerans sp. nov., isolated from a saline soil in the west of China. Int J Syst Evol Microbiol 55, 67-70.

MacKenzie, S. L. (1987). Gas chromatographic analysis of amino acids as the N-heptafluorobutyryl isobutyl esters. J Assoc Off Anal Chem 70, 151-160.

Orla-Jensen, S. (1919). The Lactic Acid Bacteria. Copenhagen: Høst and Son.

Park, H. Y., Kim, K. K., Jin, L. \& Lee, S.-T. (2006). Microbacterium paludicola sp. nov., a novel xylanolytic bacterium isolated from swamp forest. Int J Syst Evol Microbiol 56, 535-539.

Rivas, R., Trujillo, M. E., Sánchez, M., Mateos, P. F., Martínez-Molina, E. \& Velázquez, E. (2004). Microbacterium ulmi sp. nov., a xylanolytic, phosphate-solubilizing bacterium isolated from sawdust of Ulmus nigra. Int J Syst Evol Microbiol 54, 513-517.

Schleifer, K. H. (1985). Analysis of the chemical composition and primary structure of murein. Methods Microbiol 18, 123-156.

Schleifer, K. H. \& Kandler, O. (1972). Peptidoglycan types of bacterial cell walls and their taxonomic implications. Bacteriol Rev 36, 407-477.

Shivaji, S., Bhadra, B., Rao, S., Chaturvedi, P., Kumar Pindi, P. \& Raghukumar, C. (2007). Microbacterium indicum sp. nov., isolated from a deep-sea sediment sample from the Chagos Trench, Indian Ocean. Int J Syst Evol Microbiol 57, 1819-1822.

Stolz, A., Busse, H.-J. \& Kämpfer, P. (2007). Pseudomonas knackmussii sp. nov. Int J Syst Evol Microbiol 57, 572-576.

Takeuchi, M. \& Hatano, K. (1998). Union of the genera Microbacterium Orla-Jensen and Aureobacterium Collins et al. in a redefined genus Microbacterium. Int J Syst Bacteriol 48, 739-747.

Tamura, K., Dudley, J., Nei, M. \& Kumar, S. (2007). MEGA4: molecular evolutionary genetics analysis (MEGA) software version 4.0. Mol Biol Evol 24, 1596-1599.

Tindall, B. J. (1990a). A comparative study of the lipid composition of Halobacterium saccharovorum from various sources. Syst Appl Microbiol 13, 128-130.

Tindall, B. J. (1990b). Lipid composition of Halobacterium lacusprofundi. FEMS Microbiol Lett 66, 199-202.

Young, C.-C., Kämpfer, P., Shen, F.-T., Lai, W.-A. \& Arun, A. B. (2005). Chryseobacterium formosense sp. nov., isolated from the rhizosphere of Lactuca sativa L. (garden lettuce). Int J Syst Evol Microbiol 55, 423426.

Ziemke, F., Höfle, M. G., Lalucat, J. \& Rosselló-Mora, R. (1998). Reclassification of Shewanella putrefaciens Owen's genomic group II as Shewanella baltica sp. nov. Int J Syst Bacteriol 48, 179-186.

Zlamala, C., Schumann, P., Kämpfer, P., Valens, M., Rosselló-Mora, R., Lubitz, W. \& Busse, H.-J. (2002). Microbacterium aerolatum sp. nov., isolated from the air in the 'Virgilkapelle' in Vienna. Int J Syst Evol Microbiol 52, 1229-1234. 